Covered in: Web of Sciences (WOS); EBSCO; ERIH+; Google Scholar; Index Copernicus; Ideas RePeC; Econpapers; Socionet; CEEOL; Ulrich ProQuest; Cabell, Journalseek; Scipio; Philpapers; SHERPA/RoMEO repositories; KVK; WorldCat; CrossRef; CrossCheck

2019, Volume 11, Issue 1, pages: 151-162 | doi: https://doi.org/10.18662/rrem/102

\section{Integrated Research of Professional Voice Disorders of Humanitarian Departments' Teachers}

\author{
Liudmyla PERETYAHA ${ }^{1}$, \\ Valentyna GRINEVA ${ }^{2}$, \\ Iryna SHULGA ${ }^{3}$, \\ Valentina KUZMICHYOVA ${ }^{4}$, \\ Maryna SHLENOVA 5 , \\ Maryna TKACHENKO ${ }^{6}$
}

${ }^{1}$ Doctor of Pedagogics, Professor, The Department of Aesthetical Education and Preschool Education Technologies, H.S. Skovoroda Kharkiv National Pedagogical University, Ukraine,

LEPeretyagaVVMakarov@gmail.com

${ }^{2}$ Doctor of Pedagogics, Professor, Head of the Primary, Pre-school and Professional Education Department, H.S. Skovoroda Kharkiv National Pedagogical University, Ukraine, kvn.grineva@gmail.com

${ }^{3}$ Candidate of pedagogical Sciences (PhD), Head of the Department of Foreign Languages, National Aerospace University "KhAI", Ukraine, shell.s2902@gmail.com

${ }^{4}$ Candidate of Pedagogical Sciences, Head of the Department of Vocal Culture and Teacher's Acting Skills, H.S. Skovoroda Kharkiv National Pedagogical University, Ukraine, 1965valentina@ukr.net

${ }^{5}$ Candidate of Philological Sciences (PhD), Senior Lectures of the Department of Documentary and Ukrainian Language, National Aerospace University "KhAI", Ukraine, m.shleneva@,khai.edu

${ }^{6}$ Candidate of Pedagogical Sciences, Assistant Professor of The Department of Theory and Methodology of Artistic Education and Conducting-Choral Training, H.S. Skovoroda Kharkiv National Pedagogical University,

Ukraine, marusyatka@ukr.net
Abstract: Purpose. To determine the main voice disorders of humanitarian departments' teachers, their reasons and effective methods to keep the voice in a health condition.

Material. In the research participated 142 teachers of H. S. Skovoroda Kharkiv National Pedagogical University and National Aerospace University - "Kharkiv Aviation Institute" ( $n=106$ women, $n=36$ men). The study involved auditory assessment of teachers' voice and questionnaire in order to determine teachers' professional voice problems and factors influenced on the status and quality of the voice.

Results. It was determine the maximum phonation time for participants of genders, the voice disorders frequency, typical problems with teachers' voice, the positive and negative factors affecting the voice system condition. Also participants answered the questionnaire's questions about voice using.

Conclusions. The study showed that teachers take their voice for granted and do not always care about it; use their voice in an unhealthy condition and they are not always aware of the negative consequences for their health.

Keywords: voice disorders; phonation time; phoniatrist; dysphonia; aphonia.

How to cite: Peretyaha, L., Grineva, V., Shulga, I., Kuzmichyova, V., Shlenova, M., \& Tkachenko, M. (2019). Integrated Research of Professional Voice Disorders of Humanitarian Departments' Teachers. Revista Romaneasca pentru Educatie Multidimensionala, 11(1), 151-162.

https://doi.org/10.18662/rrem/102 


\section{Introduction}

Voice is the main tool of the teachers' professional activity. The voice disorders could lead to:

- quality reduction of professional activity. The profession of a teacher belongs to professions with high requirements to voice quality according to the International Classification of European Phoniatrist (UEP). Therefore even minor voice troubles reduce not only the quality of perception, but also the absorption of educational information by the audience;

- negative professional consequences. It is determined that teachers are the largest and most vulnerable professional group among all representatives of all vocal professions. According to K. Verdolini et al. (2002) teachers are predisposed to voice troubles in 32 times more often than the average person. Thus, despite of the fact that teachers are only $4 \%$ of the total working population, they occupy the first place among the representatives of all the vocal professions who are patients of phoniatrists (approximately 20\%).

The special disturbance provokes the fact that voice disorders appear at the most working age (25-55 years) (Lavrova, 2009) and lead to incapacity for work, forcing teachers to change their occupation untimely. This situation deprives a society of skilled personnel;

- negative economic consequences. According to E. Smith et al. (1998), annually in the USA about 28 million people have voice troubles that negatively affect their work and quality of life. For example, more than $20 \%$ of Iowa teachers (USA) miss the work due to voice loss Disability payments for teachers in the USA are about 2.5 billion annually.

According to T. Shidlovska (2011) during Ukrainian teachers' prophylactic examinations there were found in 3.5 times more voice disorders than it was registered by the sickness certificates. According to the results of T. Shidlovska's (2011) questionnaire more than half of respondent teachers didn't seek medical advice. i.e, the real level of teachers' voice troubles is much higher. Consequently, Ukrainian teachers with voice disorders, as a rule, do not seek medical advice, but continue to use the vocal apparatus in unhealthy condition, without a clear idea of the negative effects on their body, which leads to chronic diseases and have tendency to relapse.

The analysis of scientific literature made it possible to conclude that violations of the voice among teachers are an urgent problem for different countries of the world. 
Rantala \& Sala (2015) researched associations between classroom conditions and teachers' voice. The results showed that indoor environment affects voice use and is associated with the health of voice organs.

Mendes et al. (2016) determined that the increase in teacher's vocal intensity correlates to high noise levels in the classroom. The evidence suggests correlation between vocal intensity and discomfort of the vocal tract, with most of the symptoms reported in greater frequency and intensity after the class.

Giannini et al. (2016) conducted the survey related to vocal symptoms dimension which compared the responses in two versions of the Vocal Production Condition - Teacher (CPV-T) questionnaire, with responses on a Likert scale and a Visual Analog Scale (VAS), in order to evaluate which is the best measurement method.

Puglisi et al. (2015) evaluated the acoustical quality in high-school classrooms through in-field measurements and self-reports. Teacher's vocal load was monitored over several working days through the Voice Care device and was related to the correspondent background noise and room acoustics.

In order to reduce the voice disorders, the international community annually celebrates the World Voice Day. More and more countries join to this event each year. World Voice Day is celebrated on 16th April. It's a time to stop and consider the significance of the human voice in every aspect of daily life, and spare a thought for vocal care.

The study is devoted to the typical professional voice troubles of humanitarian departments' teachers in order to find effective ways to reduce the vocal disorders.

\section{Materials and methods}

Participants. The study involved 142 teachers of H. S. Skovoroda Kharkiv National Pedagogical University and National Aerospace University - "Kharkiv Aviation Institute" ( $\mathrm{n}=106$ women, $\mathrm{n}=36$ men). We obtained the informed consent from all the people who participated in the research.

Participants had the following specific characteristics:

- gender: women - 106 (74,6\%) and men - 36 (25,4\%);

- marital status: married - 71 participants (50\%), single - $55(38,7 \%)$, not answered - $16(11,3 \%)$;

- education: teachers (without a scientific degree) - $14(9,8 \%), \mathrm{PhD}-$ 83 (58,5\%), Dr. habil. - 29 (20,5\%), not answered -16 (11,2\%); 
- work experience: up to 5 years - 14 (9,8\%), 6-10 years - 29 $(20,4 \%), 11-15$ years $-30(21,2 \%), 16-20$ years $-48(33,9 \%)$, more than 21 years $-21(14,79 \%)$;

- weekly workload: up to 15 hours - 23 persons (16,2\%), 15-20 hours - 68 participants $(47.8 \%)$, more than 20 hours - 51 participants $(36 \%)$.

\section{Design of research}

The study of the voice function began with an auditory assessment of teachers' voice. During an individual conversation, every examinee introduced him within 3 minutes. The status of the teachers' voice was determined in consequence of the interviews. The determination of the maximum phonation time (MPT) was done for the purpose of a detailed study of the functional state of the vocal apparatus of the teachers. The teachers were offered to pronounce vowels loudly and at a convenient level after long inspiration and without tension. The length of the pronunciation was measured applying the electronic stopwatch sequentially for the vowels "a“, "O", " $\mathrm{i}$ ". The result was estimated at the average data by MS Excel.

This study is a descriptive, transversal and quantitative. Teachers were offered a questionnaire to determine what professional voice problems had lecturers, what factors influence on the status and quality of the voice, what methods are applied to improve the voice, etc. The questionnaire was developed by a group of authors led by L. Peretyaga (2016).

The various forms and methods of work were applied: workshops, conversation-lectures, individual and group consultations, conversations. The talk-lecture called "Voice Is the Main Tool for the Professional Activity of the Teacher" was held in order to increase the interest of teachers and to draw attention to the problem of improving the voice qualities. The lecture provided for direct contact with the audience, free exchange of opinions, allow the use of collective experience and knowledge, provided a discussion on "Is It Necessary To Formulate Vocal Culture In Future Teachers And Who Should Do It?". Teachers were offered a series of lecture aimed at expanding and systematizing knowledge of the voice.

\section{Results}

The results of the study determined that at the time of the study, a healthy voice, i.e. a voice that was pleasant to hearing, with sufficient strength, without additional anesthesia, urticaria and breathing instructors had 104 teachers (73,2\%); dysphonia (partial violation of strength, height 
and voice) was detected in 38 teachers (27\%); aphonia (voice loss) - wasn't diagnosed.

The results of determination the maximum phonation time (MPT) of teachers are given in tables $1 \mathrm{a}$ and $1 \mathrm{~b}$.

Table 1a. The maximum phonation time (MP'T) in men

\begin{tabular}{|c|c|c|c|c|c|c|c|}
\hline \multicolumn{2}{|c|}{ Participants } & \multicolumn{2}{|c|}{$\begin{array}{l}\text { Below the norm } \\
\text { (in less than } 20 \mathrm{sec} \text { ) }\end{array}$} & \multicolumn{2}{|c|}{$\begin{array}{l}\text { Norm } \\
(20 \mathrm{sec})\end{array}$} & \multicolumn{2}{|c|}{$\begin{array}{c}\text { Above the norm } \\
\text { (for a } 20 \mathrm{sec} \text { ) }\end{array}$} \\
\hline $\begin{array}{c}\text { Number } \\
\text { of } \\
\text { participants }\end{array}$ & $\%$ & $\begin{array}{c}\text { Number } \\
\text { of } \\
\text { participants }\end{array}$ & $\%$ & $\begin{array}{c}\text { Number } \\
\text { of } \\
\text { participants }\end{array}$ & $\%$ & $\begin{array}{c}\text { Number } \\
\text { of } \\
\text { participants }\end{array}$ & $\%$ \\
\hline 36 & 100 & 9 & 25 & 20 & 55,5 & 7 & 19,5 \\
\hline
\end{tabular}

Table 1b. The maximum phonation time (MPT) in women

\begin{tabular}{|c|c|c|c|c|c|c|c|}
\hline \multicolumn{2}{|c|}{ Participants } & \multicolumn{2}{|c|}{$\begin{array}{l}\text { Below the norm } \\
\text { (in less than } 15 \mathrm{sec} \text { ) }\end{array}$} & \multicolumn{2}{|c|}{$\begin{array}{l}\text { Norm } \\
(15 \mathrm{sec})\end{array}$} & \multicolumn{2}{|c|}{$\begin{array}{c}\text { Above the norm } \\
\text { (for a } 15 \mathrm{sec} \text { ) }\end{array}$} \\
\hline $\begin{array}{l}\text { Number } \\
\text { of } \\
\text { participants }\end{array}$ & $\%$ & $\begin{array}{c}\text { Number } \\
\text { of } \\
\text { participants }\end{array}$ & $\%$ & $\begin{array}{c}\text { Number } \\
\text { of } \\
\text { participants }\end{array}$ & $\%$ & $\begin{array}{c}\text { Number } \\
\text { of } \\
\text { participants }\end{array}$ & $\%$ \\
\hline 106 & 100 & 59 & 55,6 & 32 & 30,2 & 15 & 14,2 \\
\hline
\end{tabular}

The maximum phonation time depends on the one hand, on breathing, and on the other - on the tone of vocal folds. Reducing MPT indicates a reduction in the tone of the vocal folds, as well as an indicator of the non-formation of respiratory support, which can be considered as one of the prognostic criteria for voice violations in the future.

The results of the questionnaire allowed to reveal a certain contradiction in the answers: 76 teachers $(53,5 \%)$ recognized that they faced voice problems, while responding to the question "Have you ever had to use a voice in an unhealthy condition?" 141 teachers (99,3\%) answered - "Yes".

The study of the voice violations frequency among teachers determined that majority of interviewed teachers - 56 teachers $(39,44 \%)$ had voice problems only occasionally ( 2 times a year). Other answers are given in the diagram. 
Diagram 1. The voice disorders frequency

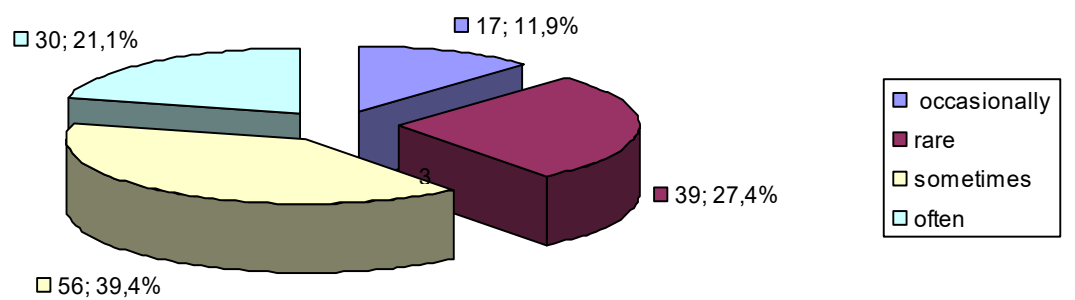

Note: the first number is the quantity of participants; the second number is the percentage value.

It was found that increase of teachers' voice loads provoke the increase of the number of voice problems and their nature. Teachers indicated the following main problems: "voice is getting strained" -21 participants (15\%); "hoarse voice" - 21 participants $(15 \%)$; "sore throat" 14 persons $(10 \%)$; "frequent laryngitis" - 12 participants $(8,6 \%)$; "aphonia“ -8 participants $(5,7 \%)$.

Diagram 2. Typical problems with teachers' voice

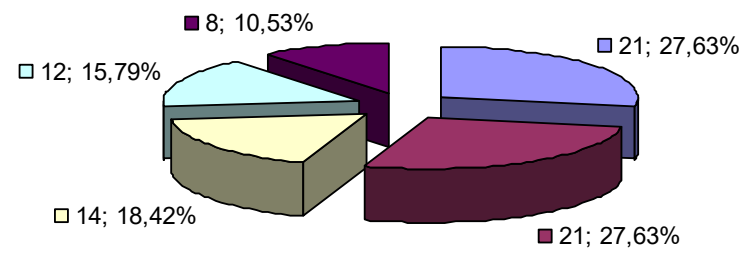

\begin{tabular}{|l|}
$\square$ voice is getting strained \\
$\square$ hoarse voice \\
$\square$ sore throat \\
$\square$ frequent laryngitis \\
$\square$ aphonia
\end{tabular}

Note: the first number is the quantity of participants; the second number is the percentage value.

The analysis of the answer to the question "Have you ever thought when entering the university that future professional activities would be associated with the increase of voice load?" determined that only 8 teachers $(5,63 \%)$ gave a positive answer; 52 participants (36,6\%) answered "no", because they had no voice problems; 28 participants $(19,7 \%)$ did not think that the future profession would be associated with the active voice use; 32 
participants $(22,6 \%)$ did not consider to do this; 22 participants $(15,4 \%)$ did not answer the question.

The analysis of the answers to the question "Who is the specialist dealing with voice problems?" revealed that not all teachers were wellinformed on this issue: 25 participants $(17,6 \%)$ did not answer; the answer "therapist" gave 21 participants (14,7\%), the answer "ENT" gave 79 participants $(55,6 \%)$, the answer "phoniatrist" gave 16 participants $(11,2 \%)$, the answer "phonopedist" gave 1 person (1\%). Teachers must know the specialists dealing with voice issues, as well as where they are and what range of problems they cure. It's necessary to ask for assistance in proper time, and to undergo periodic health examination annually.

The analysis of the teachers' answers to the question 'What affects positively to the state of voice system condition?" allowed to reveal insufficient level of knowledge on this issue. The data presented in the table 2.

Table 2 . The positive factors affecting the voice system condition

\begin{tabular}{rlcc}
\hline No & \multicolumn{1}{c}{ Positive factors } & $\begin{array}{c}\text { Number } \\
\text { of persons }\end{array}$ & $\mathbf{\%}$ \\
\hline 1. & Silence & 44 & 30,9 \\
2. No overloads & 16 & 11,3 \\
3. & Medicines & 14 & 9,8 \\
4. No infection & 12 & 8,5 \\
5. & Good mood & 8 & 5,6 \\
6. & Good weather conditions & 6 & 4,3 \\
7. Exercises for voice & 4 & 2,8 \\
8. & Hot drinks & 2 & 1,4 \\
9. & Not answered & 36 & 25,4 \\
\hline & Total & 142 & 100 \\
\hline
\end{tabular}

Particular concern is the fact that among the answers about factors affecting the voice system condition was "hot drinks". This is incorrect because they on the contrary lead to additional traumatism (burns) of the mucous membrane of the larynx.

The analysis of teachers' answers to the question "What negatively affects on the voice system condition?" also allowed to identify insufficient level of teacher's knowledge (table 3). 
Table 3. The negative factors affecting the voice system condition

\begin{tabular}{clcc}
\hline No & \multicolumn{1}{c}{ Negative factors } & $\begin{array}{c}\text { Number } \\
\text { of persons }\end{array}$ & $\mathbf{\%}$ \\
\hline 1. & Voice loads during work & 30 & 21,1 \\
2. & Raise voice (scream) & 18 & 12,6 \\
3. & Absence of early treatment & 14 & 9,8 \\
4. & Infections & 14 & 9,8 \\
5. & Stress & 12 & 8,4 \\
6. & Cold food, drinks & 10 & 7,04 \\
7. Smoking & 6 & 4,2 \\
8. & Incorrect dietary regime & 4 & 2,8 \\
9. & Not answered & 34 & 24 \\
\hline & Total & 142 & 100 \\
\hline
\end{tabular}

The answers to the question "How do you support your voice in a healthy condition?" were as follows: "take medicines and essential oils" -48 participants $(33,8 \%)$; "try to be in calm condition" -29 participants $(20,4 \%)$; "use a gargarism" - 26 participants $(18,3 \%)$; "helps vocal experience" -9 participants (6,3\%); "helps humor" -1 person $(0,7 \%)$; "did not answer the question" -29 participants $(20,5 \%)$.

Habits and behavior are the main agents that influence the human health formation. The questionnaire provided the study of teachers' voice habits, which determined that teachers drink a few water: 0-2 glasses - 44 participants (31\%), 3-4 glasses - 38 participants (26,7\%), 5-6 glasses -24 participants $(16,9 \%), 7-8$ glasses -7 participants $(4.9 \%)$, not answered -29 participants $(20,5 \%)$.

During the active use of the voice, never drink water - 47 participants $(33 \%)$, occasionally -42 participants $(29,5 \%)$, sometimes -26 participants $(18.3 \%)$, always -15 participants $(10,5 \%)$, did not answer -12 participants $(8,4 \%)$. Majority of teachers do not have the habit of moistening the larynx during active use of the voice. They drink coffee (which removes liquid from the body) in order to support themselves in a tonus. All this leads to the drying of the mucous membrane of the larynx and trauma of the vocal folds.

The majority of teachers do not "warm up" the voice before active use. 118 participants (83\%) answered "never", and only 9 teachers $(6,3 \%)$ answered "always", they were teachers of vocal disciplines who know about the need to prepare the voice before active use and do it for safety use; did not answer -25 participants $(17,6 \%)$ 
Particular concern is the fact that teachers spend a lot of time communicating on a mobile phone: up to $10 \mathrm{~min}-24$ participants $(16,9 \%)$; 10-30 min - 29 participants (20,4\%); 30-60 min - 21 participants $(14,8 \%)$; $60 \mathrm{~min}$ and more -42 participants $(29,6 \%)$; in different ways - 19 people $(13,4 \%)$; did not answer -7 participants $(4,9 \%)$. It was determined that voice problems were more expressed in teachers who often talk for a long time on a mobile phone (more than $60 \mathrm{~min}$ ). Teachers should know that 20 min of conversations on a mobile phone is equal to 1 hour of voice load.

The responded teachers do not smoke, but 52 persons $(36,6 \%)$ often become a passive smokers, which also negatively affects their vocal folds.

Teachers were asked to estimate the level of their own voice on a scale from 1 to 10 (where 1 - the minimum score, and 10 - the maximum). The results of the questionnaire were as follows: $1-2$ points -0 person; $3-4$ points -7 participants $(4,9 \%)$; $5-6$ points -51 participants $(35,9 \%) ; 7-8$ points -66 participants $(46,4 \%)$; $9-10$ points -12 participants $(8,45 \%)$; did not answer -6 participants $(4,2 \%)$.

Teachers demonstrated a high level of readiness to improve their own skills and the desire to learn more about how to maintain a voice in a healthy conditions: $1-2$ points -0 person, 3-4 points -0 person, 5- 6 points 0 person, $7-8$ points -66 participants $(46,4 \%)$, 9-10 points -74 participants $(52,1 \%)$.

\section{Discussion}

The questionnaire allowed revealing the fact that some teachers experienced voice problems for a long time (from two months to several years). The most common teachers' voice disorders are: phonasthenia, chronic laryngitis, nodules of vocal folds, chronic dysphonia.

The female teachers (73 persons) have voiced disorders more frequently than men. It is explained by the peculiarity of the vocal system such as:

- peculiarity of the vocal folds structure. Men have longer (19-22 $\mathrm{mm})$ and wider (3,4-4,5 $\mathrm{mm})$ vocal folds, while women have shorter and thinner vocal folds (length $14 \mathrm{~mm}$, width $2 \mathrm{~mm}$ );

- functioning features. The vocal folds of women carry out more vibrations: $160-340$ vibrations per sec., whereas men carry out only 85-200 vibrations per sec.;

- hormonal changes affecting the condition of the female voice (monthly during menstruation, taking hormones, during pregnancy and climax); 
- high emotionality; women are more emotional than men, which negatively affects the voice condition. Consequently, the peculiarity of the anatomical structure of female teachers' vocal folds makes them more vulnerable and prone to voice disorders.

Particular concern is the fact that the prevalence of voice disorder in our country is not only high but continues to increase rapidly from $30-40 \%$ (30s-60s of the $20^{\text {th }}$ century) up to $55-60 \%$ of the 90 s years of the $20^{\text {th }}$ century (Orlova, 2008). According to the data of 2011, $86 \%$ of secondary schools teachers have functional voice disorders (Shidlovska, 2011), i.e., such disorders of the vocal function, in which there are no expressed organic disorders in the vocal system, but there are certain disorders of phonation (change in timbre, intensity, voice modulation, motor and vibrational ability of vocal folds, etc.).

The teachers-beginners have the most propensities for voice disorders. According to O. Orlova (2008), already in the first year of work $55 \%$ of young teachers have different degrees of voice disorders, and in the first three years of work $-72 \%$, which suggests that most graduates of pedagogical educational institutions are not properly prepared for voice loads, because they can not correctly and effectively use their voice.

The increasing percentage of voice disorders among teachers makes the problem of vocal culture formation in universities teachers particularly relevant, because the voice of the higher educational institution teacher, the manner of his communication with the audience is an example for future teachers.

The series of theoretical and practical classes was developed and conducted by the authors from August 29 to September 2, 2018 in order to solve this problem. It was not accidental, because voice problems usually appear in teachers at the beginning of the study year, which is due to unequal distribution of the voice load during the study year and its rapid increase in September after a long summer vacations, when there is no need to speak long and loud. The first period of maximum vocal load coincides with the beginning of the first studying semester (September to December), and the second semester (January to May).

Particular attention was paid to familiarizing teachers with specialists and the range of problems which they cure. The teachers were explained that the phonopedist is a logopedist specializing in the field of phonopedia and is engaged in training the skills of pedagogical techniques of correct voice using; phoniatrist - is otolaryngologist (ENT), specializing in phoniatrics, is engaged in diagnostics, treatment and prevention of vocal 
system disorders. In the absence of a phoniatrist it is necessary to address an otorhinolaryngologist.

It should be noted that the teachers actively participated in conversations, discussions, in the course of which there were discussed issues related to the vocal culture formation. The particular interest had the proposed additional scientific and methodical literature, which revealed some aspects of the vocal culture formation. Also, the teachers were offered training systems, which aimed to improve the work of the vocal system.

\section{Conclusions}

The results of the questionnaire showed that teachers take their voice for granted and do not always care about it; use their voice in an unhealthy condition and they are not always aware of the negative consequences for their health. They usually visit the doctor only when they lose their voice. Meanwhile, teachers show a high level of readiness to improve their own voice quality.

The results of the study allow the conclusion that attending lectures and training by teacher allowed to prepare them for vocal load and helped to master the methods of correct and effective use of the vocal system, and also contributed to the expansion of knowledge of the voice and the means of maintaining it in a healthy condition.

\section{Conflict of interests}

The authors declare that there is no conflict of interests.

\section{References}

Giannini, S. P., Latorre Mdo, R., Ferreira, L. P. (2016). Condition of Vocal Production-Teacher questionnaire: comparison of responses on Likert scale and visual analog scale. Codas, 28(1), 53-8. doi:10.1590/2317$1782 / 20162015030$

Lavrova, E. V. (2009). Znachenie postanovki golosa v profilaktike vozniknoveniya golosovyh rasstrojstv. Golos: mezhdisciplinarnye problemy. Teoriya i praktika: sb. nauch. tr. II kongressa Rossijskoj obshestvennoj akademii golosa. M.: Granica.

Mendes, A. L., Lucena, B. T., De Araújo A. M., Melo, L. P., Lopes, L. W., Silva, M. F. (2016). Teacher's voice: vocal tract discomfort symptoms, vocal intensity and noise in the classroom. Codas, 28(2), 168-75. doi:10.1590/2317$1782 / 20162015027$

Orlova, O. S. (2008). Narusheniya golosa. M.: Astrel. 
Peretyaga, L. E. (2016). Teoretiko-metodologichni zasady formuvannia golosovoii kultury maibutnikh uchyteliv u protsesi profesiinoii pidgotovky: avtoref. dis. na zdobuttia nauk. stupenya dok.t. ped. nauk: spec. 13.00.04 "13.00.04". Kharkiv.

Puglisi, G. E., Cantor Cutiva, L. C., Pavese, L., Castellana, A., Bona, M., Fasolis, S., Lorenzatti, V., Carullo, A., Burdorf, A., Bronuzzi, F., Astolfi, A. (2015). Acoustic comfort in high-school classrooms for students and teachers. Energy Procedia, 78, 3096-3101. doi:10.1016/j.egypro.2015.11.763.

Rantala, L. M., Sala, E. (2015). Associations between classroom conditions and teacher's voice production. Energy Procedia, 78, 3120-3125. doi:10.1016/j.egypro.2015.11.767

Shydlovska, T. A. (2011). Funktsionalni porushennia golosu. K: Logos.

Smith, E., Lemke, J., Taylor, M., Kirchner, H. L., Hoffman, H. (1998). Frequency of voice problems among teachers and other occupations. J Voice, 12, 480488. doi:10.1016/S0892-1997(98)80057-X

Verdolini, K., Min, Y., Titze, I., Lemke, J., Brown, K., van Mersbergen, M., Jiang, J., \& Fisker, K. (2002). Biologic mechanisms underlying voice changes due to dehydration. Journal of Speech, Language and Hearing Research, 45, 268-281. 